\title{
Assessing intellectual capital management by fuzzy TOPSIS
}

\author{
Hossein Jannatifar, Mohammad KazemKeshvar Shahi and Javad Siahkali Moradi*
}

M.A. in Industrial Management, Islamic Azad University, Tehran, Iran

\begin{tabular}{l}
\hline A R T I C L E I N F O \\
\hline Article history: \\
Received April 17, 2012 \\
Accepted 11 June 2012 \\
Available online \\
June 152012 \\
\hline Keywords: \\
Models of evaluating intellectual \\
capital management \\
Fuzzy TOPSIS \\
Criteria of suitable model
\end{tabular}
A B S T R A C T

\begin{abstract}
Intellectual capital is a type of asset measuring ability of economic agency in order tomake wealth. These assets do not have physical and objective nature and are intangible assets being achieved through utilization of relative assets with human resources, organizational operation and foreign relations from economic agency. Measuring this issue is important from intraorganizational and extra-organizational views. In this paper, we present survey based on Fuzzy TOPSIS to find important factors influencing intellectual capital management. The proposed model of this paper considers different factors, which exist in the literature and prioritize them based on different criteria. The results of our survey identified seven items as the most influencing factors.
\end{abstract}

\section{Introduction}

$21^{\text {st }}$ century is well known as the knowledge based economy and industrial economy was dominated before knowledge based economy. A series of physical and tangible assets such as ground, human resource, money and technology were economical wealth factors in this economy so that wealth was produced by combination of these economic factors. Using knowledge as a productive factor plays a weak role in this economy, but knowledge or intellectual capital has more priority as a productive factor of wealth compared with other tangible and physical assets.

Intellectual capitals especially human investments are accounted as the most important organizational asses in this economy and potential success of organizations come from their intellectual capabilities rather than their tangible assets (Flamholtz et al., 2002). With the growth of science economy based on knowledge, we observe that intangible assets of companies are important factors in protection and achievement of stable competitive benefit compared with other tangible assets (Tayles, 2002). Kendrick (1990) is one the most famous economists in US who believes that percentage of intangible commercial assets to tangible commercial assets were 30\% to $70 \%$ in 1929 in 1990. In addition, Leo mentions that about $10 \%$ to $15 \%$ of total percentage of marketing value of companies includes

\footnotetext{
* Corresponding author. Tel: +989122520885

E-mail addresses: syahkaly@gmail.com (J. Siahkali Moradi) 
physical and tangible assets and about $85 \%$ of marketing value of companies includes intangible assets that no activity has been accomplished for their measurement (Seetharaman 2002). In 1999, some studies were done in the area of combining thousands of non-financial companies from 1978 to 1998, which indicated that relationships between tangible and intangible assets were considerably changed. In 1978, percentage of tangible and intangible assets was from $80 \%$ to $20 \%$, but in 1998 this percentage reached from $20 \%$ to $80 \%$. This considerable change brings about a series of methods for accounting wealth of companies that their important assets were intangible assets specially intellectual and learned assets (Sullivan, 2002).

During the past decade, businesses perceived importance of intangible assets and advancement of marks, stockholders' relations, popularity and culture of organizations were considered as the most important resources of stable benefit. In this economy, ability of making and using value of these intangible assets created a principle competence for organization (Kannan, 2004). Measurement of intellectual asset is important with two aspects. Goal of intra-organization is better specialization of resources in direction of proficiency and minimizing organizational cost and aim of extraorganization is to achieve the existent investments information and potential of organization in order to predict future growth and long time programs. In order to achieve complete picture of operational functions and evaluate value of organization, all aspects of organization is assessed. Usual method of measurement based on traditional accounting cannot lonely succeed in this activity (Roos et al., 1997). In this article, it is attempted to assess measurement models of intellectual capital by indexes.

\section{Theoretical frame}

\subsection{Concepts and definitions of intellectual capital}

Intellectual capital is created from science and knowledge and still, this term maintains its own growth. Many systems are using intellectual capital, but many people do not have any information about organizations and economic agencies. Concept of intellectual capital has been frequently discussed, but it is not defined well and different words have been used for interpreting this concept. People attend to use terms like, assets, resources or motivations of function rather than capital. They utilize intellectual word instead of words like, intangible on the basis of financial or non-financial science. Some of proficiencies (such as financial accounting, accounting ...) present different definitions like non-financial fixed assets not having objective and physical existence, but are maintained, controlled and recognized through legal rights by economic agencies (Marr, 2008). Stewart believes that intellectual capital is a collection of knowledge, information, intellectual properties, experience, competition and organizational learning, which can be used to make wealth. In fact, intellectual capital of all personnel involves organizational knowledge and their ability for creating value added and cause competitive benefit (Tissen, 1998).

Edvinsson and Malon say that intellectual capital of information and knowledge are used for accomplishment and utilization (Vasile, 2008). Bentis and Holand (2002) believe that intellectual capital is a store of knowledge being in a special point of time in an organization or economic agency. In this definition, relations between intellectual capital and organization learning have been considered (Vasile, 2008). Recently, researchers presented complete definition about intellectual capital and a necessary requirement has been mentioned for recognizing these assets. Intellectual capital is a type of asset that measures ability of economic agency for fulfilling wealth. This asset does not contain objective and physical nature and it is an intangible asset achieved through utilization of relative assets with human resources, organizational operation and foreign relations from economic agency. All these characteristics bring about accomplishing value in intra organization and cannot be sold or bought since achieved value is an intra-organizational phenomenon (Rose\& Barons, 2005). 


\subsection{Measurement of intellectual capital}

In order to manage something like intellectual capital, we must be able to first measure it (Sanchez, 2000). Hence, we attend to reasons of measuring intellectual capital by companies in the century of scientific economy. Reviewing systematic literature of why companies do not measure their intellectual capital, these people remarked five principle reasons for this issue on why we should measure and why companies do not measure their intellectual capital. Some of the reasons are

1. to help organizations for adjustment of their strategy,

2. to asses fulfillment of strategies,

3. to help advanced and various decisions,

4. to use result of measuring intellectual capital as a base for compensate,

5. and to serve these relative criteria to intellectual capital to shareholders and concerned foreigners.

Other reasons

6. Measuring intellectual capital can completely measure value and their operations. In a society based on knowledge, knowledge is an important part of value of a good and constitutes wealth of a company. Traditional models and accounting methods based on tangible assets as well as deal and date cannot measure these values (Kannan et al., 2004; Chen et al., 2004).

7. Assessment of return rate of capital: it is measured for quantity of hard and soft benefits of investments like education and improvement of intellectual capital.

8. Managerial control: it is for making quantity of individual value and their technical knowledge instead of having simple perception of costs as a help for decision making in operational level.

9. Future programming: if the most important and valuable assets are able to create principle capability and competitive benefit for organization in future or not?

10. Assessment of organization: it is for condition that organization is dissolved or combined or acquired (Tyles et al., 2002).

11. Companies should follow measuring and management of intellectual management in order to have better perception from fulfilling process and significant amendment in their operation (Guthrie et al., 2001).

\subsection{Measuring intellectual capital: models and methods}

The most principle process of measuring intellectual capital is as follows,

1. Strategic management model of capability proposed capability,

2. Economic value added,

3. Technological model of Brooker,

4. Intellectual capital,

5. Observer of intangible assets,

6. Balanced score card,

7. Human resource accounting.

\subsubsection{Strategic management model of capability}

Bueno defines intellectual capital as a collection of distinct principle capabilities, which includes intangible nature and protects competitive benefit for organization. The formula is as follows, Intellectual capital= human capital + organizational capital + technological capital + relative capital

\subsubsection{Economic value added}

Another measurement which is widely used by big companies is economic value added and this method was presented by Stewart in 1980 decade. Economic value added is a complete criterion, which joins capital budgeting, financial programming, aiming and operational measurement, etc. 
However, economic value added is not expressly related to benefit management and intangible assets, but it implicitly indicate to this point that effective management of capital assets increases economic value added. This process looks at company as a traditional industrial organization rather than looking on the base of scientific management and emphasizes on financial indexes (Chen et al., 2004).

- Difficulties of this process

Difference between official value and marketing value cannot be completely and individually assigned to intellectual assets and some part of these differences are associated within tangible assets in company balance. Other difficulty is that share prices may have oscillation from one day to another and provides short time uncertain information about measuring intellectual assets.

\subsubsection{Technological model of Brooker}

Brooking believes that marketing value of a company includes 2 factors as follows,

- Tangible assets

- Intangible assets

and intangible assets are divided into 4 classes:

- Marketing values (customers and brands)

- Human resources (education, working knowledge and skills)

- Skills of moral possession (loyalty, copy write, design authority and commercial secrets)

- Substructure assets (culture, informative system and business philosophy).

\subsubsection{Intellectual capital}

Intellectual capital became famous as a concept in $90^{\text {th }}$ and intensity of interest to it became more and more and the first attention and interest to it was by assurance industrial companies of Sweden. Edvinss on and Malone presented a dynamic and holism report model of intellectual capital in the name of IC Skandia Navigator. According to this model, intellectual capital is classified in 2 structural and humane capitals. This classification of intellectual capital became famous in the name of distinct value tree that has been shown in Fig. 2.

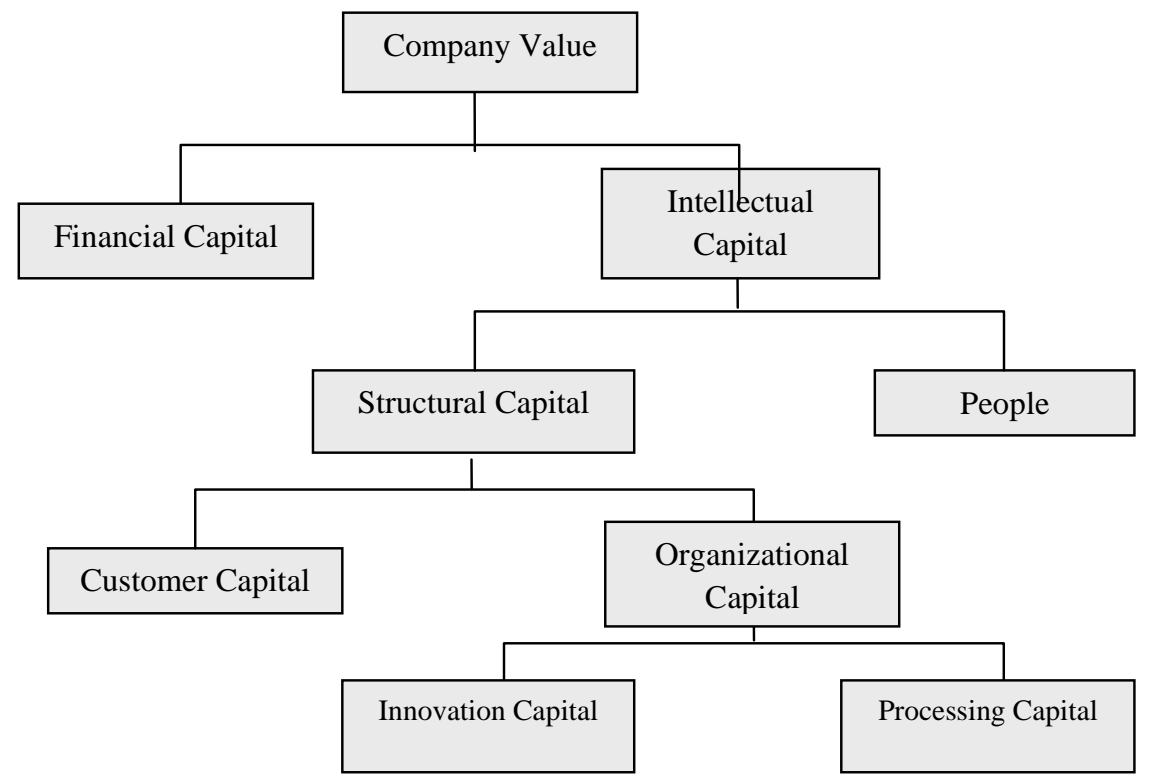

Fig.1. The structure of distinct tree (Chen et al., 2004) 
Note that this diagram either includes financial criteria or non-financial criteria, which can be combined to estimate marketing value of a company. Now, many companies use this diagram for measuring loyalty, research, advancement and its monetary representation in balance sheet. This index ignores many intellectual capitals like culture, organizational learning, and personnel innovation having the most important role in fulfilling value. In addition, most of its assumption is wrong, therefore, it should be said that many of its issues need to be reformed and simplified (Chen et al., 2004).

\subsubsection{Observer of intangible asset}

In this approach against balanced score card, people are considered as generators of benefit and value and are destitute of proposed financial view in balanced score card. Finally is should said that some of measured models require collection of plenty information and are not furnish general public and it is only for suitable management, whereas some of them either for foreign or in land user of company are suitable (like percentage of marketing value to official value) (See Table 1).

\section{Table 1}

Observable representation of intangible assets (Kenndy 1998)

\begin{tabular}{|c|c|c|}
\hline Extra structure & Intra structure & Competencies \\
\hline Indexes of growth and remake & Indexes of growth and remake & Indexes of growth and remaking \\
\hline Profit making of every customer & Investment in systems & Costs of education \\
\hline \multirow{3}{*}{ Organic growth } & Help of customers for improving & Service leaving \\
\hline & processing systems & Level of education \\
\hline & & $\begin{array}{l}\text { Years and duration of personnel } \\
\text { specialization }\end{array}$ \\
\hline Proficiency indexes & Proficiency indexes & Proficiency indexes \\
\hline \multirow{4}{*}{$\begin{array}{l}\text { List of satisfied customers } \\
\text { Annual sale of every customer }\end{array}$} & Percentage of supportive personnel to all & Value added of every personnel \\
\hline & personnel & Axis effect \\
\hline & Percentage of sale in favor of every & \\
\hline & Polling company culture & \\
\hline Resistance indexes & Resistance indexes & Resistance indexes \\
\hline Olden structure of customers & Old of organization & Olden average \\
\hline Percentage of devoted customers & Rate of leaving supportive personnel & Seniority \\
\hline Plenty of repeated orders by & serving & Rate of leaving professionals' \\
\hline
\end{tabular}

Edvinsson emphasized that an organization should measure criteria and indexes being strategically important for future growth and guidance of company, on the other hand, Sveiby believes that selection of these criteria and indexes is depended on strategy of company.

\subsubsection{Human resource accounting}

Beginning and growth of this system was started by Hermanson's studies that caused accomplishment of discussion and advanced researches for measuring intangible assets among accountants and theorists of human resources. The primary aim of human resource accounting is the quantity building economic value of people for organization to provide inputs for financial and managerial decisions. There are three suggested types of measuring models for human resource accounting, which includes cost models, human resource value models and monetary models.

Due to considerable assistance being fulfilled by human resource accounting for measuring intangible assets, it can be considered as an important index of measuring intellectual capital. Models of human resource accounting of human capitals are assessed on the basis of financial words. These models are widely used in services organization where human resources considerably constitute value of 
organization; but all these models attend to be unstable, variable and conceptual, so they have very low assets. In this approach, people are considered as human resources. In past, accounting methods interfered with human resource costs as current costs that reduce net income of company. However, in new view, (human resource accounting)these human resource costs are regarded as an investment following a series of benefits and profits for company future. Now, human resource is studied in the section of balanced sheet assets (Chen et al., 2004).

\section{Functions of human resource accounting}

- To provide numeral information about cost and value of people as organizational resource

- To act as analysis frame for facilitating decision making.

- To cause motivation of decision makers for taking a view of human resource management.

\subsection{7. balanced score card}

After several year studies and assessment of various companies, Norton and Kaplan suggested that managers need measuring multi dimension system for guiding policies and proposed balanced score card for assessment of function. In fact, this was for the first time that companies were motivated to contemporary measurement of financial and non-financial factors. This approach thinks over customer perspectives, internal processes, learning and growth, finance, and way of connecting them in a dependent and organized system. Although, the concept of balanced score card was proposed before the concept of intellectual capital, but the idea of balanced score card and intellectual capital measurement can get to an aim with different methods. Though, balanced score card has important complement role in fulfilling balance in traditional views, because it adds financial views and criteria. It should note that balanced score card emphasizes more on customer and financial views.

\section{Research methodology}

In current research, some of ideas about management of intellectual capital has been assessed and has been compared by fuzzy multi criteria decision making method and 11 criteria were introduced for a theory (Bontis, 2001).

\section{Table 2}

Criteria of theory assessment (Bontis, 2001)

\begin{tabular}{|c|c|}
\hline Criteria & Expression \\
\hline Conservatism & $\begin{array}{l}\text { A new theory cannot be replaced instead of existent theory, unless new theory has } \\
\text { satisfied reasons. }\end{array}$ \\
\hline Incomparable & Meaning that theory should be incomparable, unified and distinct from other theory. \\
\hline Generalization & $\begin{array}{l}\text { Numbers of areas in which theory can be loyal and applicable; how these areas be more, } \\
\text { importance of theory is more }\end{array}$ \\
\hline $\begin{array}{l}\text { Capability of representing } \\
\text { idea }\end{array}$ & $\begin{array}{l}\text { If a theory would have capability of producing models and more assumption, it would be } \\
\text { primitive. }\end{array}$ \\
\hline Limitation of theory & If theory has little limiting assumptions, it includes better priority towards other theories. \\
\hline Simplicity and effectiveness & $\begin{array}{l}\text { Simple language and perception of theory is the distinctive of a theory which } \\
\text { characterized complex and difficult theories in transferring concepts. }\end{array}$ \\
\hline $\begin{array}{l}\text { Independent form time and } \\
\text { place }\end{array}$ & $\begin{array}{l}\text { Meaning that a theory should be independent from time and place and be loyal on the } \\
\text { basis of its relations and variables. }\end{array}$ \\
\hline Risk of fulfillment & Tests and experiences always face with dangerous \\
\hline Clear and unambiguous & $\begin{array}{l}\text { Meaning that a theory should be apparent and its concept and aim be clear. So that it can } \\
\text { provide different definitions and interprets. }\end{array}$ \\
\hline $\begin{array}{l}\text { Concordant and internal } \\
\text { stability }\end{array}$ & $\begin{array}{l}\text { Meaning that components and factors which theories having should be logical and } \\
\text { concordant in variables }\end{array}$ \\
\hline $\begin{array}{l}\text { Output popularity and results } \\
\text { of theory }\end{array}$ & $\begin{array}{l}\text { Output and results of theory should be turning to attractive, beautiful and kicky, not it } \\
\text { has other words and paid to the points which have been previously paid to. }\end{array}$ \\
\hline
\end{tabular}


Making model is based on FUZZY TOPSIS, which is a popular method. The first level of that aims the end level of competitive alternatives and middle levels of decision making criteria. In the method of FUZZY TOPSIS, it is asked from participators being selected from some of experts to compare and give score weight of studied matrix.

\section{Analysis of information}

\subsection{Fuzzy TOPSIS}

In multi index decision making, some of alternatives are analyzed and one type of priority is accomplished. Sometimes, solutions and selection of suitable models is sued instead of its synonyms like strategy. In addition to consider distance of an alternative $A_{i}$, from positive ideal, negative ideal is considered too; so that regarded alternative involves the lowest distance from positive ideal and highest distance from negative ideal.

Step 1: turning fuzzy matrix of decision making to fuzzy unmeasured matrix:

$$
R=\left[\begin{array}{ccccc}
r_{11} & \cdots & r_{1 j} & \cdots & r_{1 n} \\
\vdots & & \vdots & & \vdots \\
r_{i 1} & \cdots & r_{j 1} & \cdots & r_{i n} \\
\vdots & & \vdots & & \vdots \\
r_{m 1} & & r_{m j} & & r_{m m}
\end{array}\right] \quad r_{i j}=\frac{x}{\sqrt{\sum_{i=}^{m}}}
$$

First, the highest and lowers score is accounted in every index. Then triangular and trapezoid fuzzy numbers of decision making matrix are normalized as the following:

For triangular fuzzy numbers:

$\tilde{r}_{i j}=\left\{\begin{array}{l}A=\tilde{x}_{i j} / \tilde{x}_{j}^{+}=\left(\frac{a_{i j}}{c_{j}^{+}}, \frac{b_{i j}}{b_{j}^{+}}, \frac{c_{i}}{a_{j}}\right), \\ B=\tilde{x}_{j}^{-} / \tilde{x}_{j}=\left(\frac{a_{j}^{-}}{c_{i j}}, \frac{b_{j}^{-}}{b_{i j}}, \frac{c_{i}}{a_{j}}\right),\end{array}\right.$

where A and B represent benefit and cost, respectively. Similarly, for trapezoid fuzzy numbers we have,

$$
\tilde{r}_{i j}=\left\{\begin{array}{l}
A=\tilde{x}_{i j} / \tilde{x}_{j}^{+}=\left(\frac{a_{i j}}{c_{j}^{+}}, \frac{b_{i j}}{b_{j}^{+}}, \frac{c_{i j}}{a_{j}^{+}}, \frac{d_{i}}{a_{j}}\right), \\
B=\tilde{x}_{j}^{-} / \tilde{x}_{j}=\left(\frac{a_{j}^{-}}{c_{i j}}, \frac{b_{j}^{-}}{b_{i j}}, \frac{c_{j}^{-}}{b_{i j}}, \frac{d_{i}}{a_{j}}\right),
\end{array}\right.
$$

Step 2: account of normalized matrix and weighted fuzzy $\tilde{v}_{i j}=\tilde{r}_{i j} \cdot \tilde{w}_{j}$

Step 3: getting answer of positive ideal and answer of negative ideal For triangular fuzzy numbers:

$$
M\left(v_{i j}\right)=\frac{-a_{i j}^{2}+c_{i j}^{2}-a_{i j} b_{i j}+c_{i}}{3\left(-a_{i j}+c_{i j}\right)}
$$

For trapezoid fuzzy numbers: 
$M\left(v_{i j}\right)=\frac{-a_{i j}^{2}-b_{i j}^{2}+c_{i j}^{2}+d_{i j}^{2}-a_{i j} b_{i j}+c_{i}}{3\left(-a_{i j}-b_{i j}+c_{i j}+d_{i j}\right)}$

Step 4: getting size of distance of every alternative towards positive and negative ideal

$$
\begin{aligned}
& A^{+}=\left\{\left(\max _{i} v_{i j} \mid j \in J\right),\left(\min _{i j} \mid j \in J^{\prime}\right) \mid i=1, \cdots, m\right\}=\left\{v_{1}^{+}, \cdots, v_{n}^{+}\right\} \\
& A^{-}=\left\{\left(\min _{i} v_{i j} \mid j \in J^{\prime}\right)\left(\max _{i} v_{i j} \mid j \in J^{\prime}\right) \mid i=1, \cdots, m\right\}=\left\{v_{1}^{-}, \cdots, v_{n}^{-}\right\}
\end{aligned}
$$

Distance of $i_{m}$ alternative from positive ideal:

$$
S_{i}^{+}=\sqrt{\sum_{j=1}^{n}\left(v_{i j}-v_{j}^{+}\right)^{2}}
$$

Distance of $i_{m}$ alternative from negative ideal:

$$
S_{i}^{-}=\sqrt{\sum_{j=1}^{n}\left(v_{i j}-v_{j}^{-}\right)^{2}}
$$

Step 5: comparative closeness account of every alternative to ideal:

$C_{i}=\frac{S_{i}^{-}}{S_{i}^{+}+S_{i}^{-}}$

Step 6: ranking alternatives from highest weight to the lowest

\subsection{Numerical example and comparing and assessing models by TOPSIS FUZZY Technique}

We analyze and assess the model regarding algorithm of fuzzy TOPSIS and algorithm is done as the following:

\begin{tabular}{|c|c|c|c|c|c|c|c|}
\hline & 1 & 2 & 3 & 4 & 5 & 6 & 7 \\
\hline \multirow{3}{*}{ A } & 0 & 0 & 0.1429 & 0.1429 & 0 & 0.4286 & 0.4286 \\
\hline & 0.1 & 0.1 & 0.4 & 0.4 & 0.1 & 1 & 1 \\
\hline & 0.5 & 0.5 & 1 & 1 & 0.5 & 2.3333 & 2.3333 \\
\hline \multirow{3}{*}{ B } & 0.85 & 0.1 & 0.7 & 0.1 & 0.85 & 0.5 & 0.3 \\
\hline & 1 & 0.2105 & 0.8421 & 0.2105 & 1 & 0.6842 & 0.5263 \\
\hline & 1.1765 & 0.3529 & 1.0588 & 0.3529 & 1.1765 & 0.9412 & 0.8235 \\
\hline \multirow{3}{*}{ C } & 0.7 & 0.2 & 0.5 & 0.5 & 0.85 & 0.3 & 0.3 \\
\hline & 0.8421 & 0.3684 & 0.6842 & 0.6842 & 1 & 0.5263 & 0.5263 \\
\hline & 1.0588 & 0.5882 & 0.9412 & 0.9412 & 1.1765 & 0.8235 & 0.8235 \\
\hline \multirow{3}{*}{ D } & 0.7 & 0.85 & 0.5 & 0.7 & 0.7 & 0.1 & 0.7 \\
\hline & 0.8421 & 1 & 0.6842 & 0.8421 & 0.8421 & 0.2105 & 0.8421 \\
\hline & 1.0588 & 1.1765 & 0.9412 & 1.0588 & 1.0588 & 0.3529 & 1.0588 \\
\hline \multirow{3}{*}{$\mathrm{E}$} & 0.85 & 0.7 & 0.2 & 0.2 & 0.1 & 0 & 0.85 \\
\hline & 1 & 0.8421 & 0.3684 & 0.3684 & 0.2105 & 0.0526 & 1 \\
\hline & 1.1765 & 1.0588 & 0.5882 & 0.5882 & 0.3529 & 0.1765 & 1.1765 \\
\hline \multirow{3}{*}{$\mathrm{F}$} & 0.1111 & 0.7778 & 0.3333 & 0.3333 & 0.5556 & 0.1111 & 0 \\
\hline & 0.25 & 1 & 0.625 & 0.625 & 0.8125 & 0.25 & 0.0625 \\
\hline & 0.4286 & 1.2857 & 1 & 1 & 1.1429 & 0.4286 & 0.2143 \\
\hline \multirow{3}{*}{ G } & 0.3333 & 0 & 0.3333 & 0.7778 & 0.5556 & 0.7778 & 0.3333 \\
\hline & 0.625 & 0.0625 & 0.625 & 1 & 0.8125 & 1 & 0.0625 \\
\hline & 1 & 0.2143 & 1 & 1.2857 & 1.1429 & 1.2857 & 1 \\
\hline \multirow{3}{*}{$\mathrm{H}$} & 0 & 0.85 & 0.1 & 0 & 0.3 & 0.2 & 0.1 \\
\hline & 0.0526 & 1 & 0.2105 & 0.0526 & 0.5263 & 0.3684 & 0.2105 \\
\hline & 0.1765 & 1.1765 & 0.3529 & 0.1765 & 0.8235 & 0.5882 & 0.3529 \\
\hline \multirow{3}{*}{ I } & 0.1111 & 0 & 0.7778 & 0.2222 & 0.7778 & 0.7778 & 0.1111 \\
\hline & 0.25 & 0.0625 & 0.4 & 0.4375 & 1 & 1 & 0.25 \\
\hline & 0.4286 & 0.2143 & 1.2857 & 0.7143 & 1.2857 & 1.2857 & 0.4286 \\
\hline \multirow{3}{*}{$\mathrm{J}$} & 0.2857 & 0.1429 & 0.1429 & 0.1429 & 0 & 0.4286 & 0.4286 \\
\hline & 0.7 & 0.4 & 0.4 & 0.4 & 0.1 & 1 & 1 \\
\hline & 1.6667 & 1 & 1 & 1 & 0.5 & 2.3333 & 2.3333 \\
\hline \multirow{3}{*}{ K } & 0.625 & 0.125 & 0.625 & 0.125 & 0.625 & 0.375 & 0.375 \\
\hline & 1 & 0.3077 & 1 & 0.3077 & 1 & 0.7692 & 0.7692 \\
\hline & 1.6 & 0.6 & 1.6 & 0.6 & 1.6 & 1.4 & 1.4 \\
\hline
\end{tabular}

Step 1: Calculation of normalized and weighted matrix (Table 3):

\section{Table 3}

Normalized and weighted matrix 
Step 2: Achievement of positive and negative ideal answer and achievement to positive and negative $\mathrm{D}_{\mathrm{ij}}$ :

\section{Table 4}

Calculating $\mathrm{S}^{-}$and $\mathrm{S}^{+}$

\begin{tabular}{llllllll}
\hline$S^{-}$ & 14.78064 & 12.76486 & 13.94869 & 10.46539 & 16.62771 & 11.6682 & 12.49852 \\
\hline$S^{+}$ & 9.812703 & 12.32762 & 8.670335 & 12.89077 & 6.721169 & 11.80313 & 10.48405 \\
\hline
\end{tabular}

Table 5

Calculating $\mathrm{C}^{+}$for each evaluation model

\begin{tabular}{lllllll}
\hline 0.601002 & 0.508712 & 0.616679 & 0.448078 & 0.712142 & 0.497126 & 0.543826 \\
\hline
\end{tabular}

Achievement of distance of every alternative towards positive and negative ideal and account of $\mathrm{D}+$ and D-, comparative closeness account of every alternative to ideal solution

And the final rank is:

$$
5>3>1>7>2>6>4
$$

1. Observer of intangible assets proposed by Sveiby

2. Technological model of Brooker proposed by Brooking

3. Strategic management model of capability proposed capability by Bueno

4. Balanced score card

5. Economic value added

6. Human resource accounting

7. Intellectual capital, Bontis et al 1999.

\section{Conclusion and suggestions}

In this paper, we have presented an empirical study on factors influencing human capital. We have used fuzzy programming technique to find the relative importance of all criteria. We have selected 11 criteria including Conservatism, Incomparable, Generalization, Capability of representing idea, Limitation of theory, Simplicity and effectiveness, Independent form time and place, risk of fulfillment, Clear and unambiguous, Concordant and internal stability, Output popularity and results of theory as suitable theories and the proposed model prioritized them using fuzzy theory, which yields the following,

1. Observer of intangible assets proposed by Sveiby

2. $\quad$ Technological model of Brooker proposed by Brooking

3. Strategic management model of capability proposed capability by Bueno

4. $\quad$ Balanced score card

5. Economic value added

6. Human resource accounting

7. Intellectual capital, Bontis et al 1999

This issue in many management discussions can help researchers in selection of suitable model in order to use different subjects. 


\section{References}

Wang, Y.M.,Elhag, T. (2006). Fuzzy topsis method based on alpha level sets with an application to bridge risk assessment.Expert System with Applicatioin, 31,309-319.

Bernnan, N. (2001). Intellectual capital annual reports: evidence from Ireland.Accounting,Auditing \& Accountability Journal , 14(4), 423-436.

Bontis, N. (1998). Intellectual capital: an exploratory study that develops measures and models. Managing Decision, 36(2), 63-76.

1 Bontis, N. (2001). ASSESSING KNOWLEDGE ASSETS:A Review of the Models Used to Measure Intellectual Capital. International Journal of Management reviews, 3(1), 41-60.

Chen,J., Zhu, Z., \& Xie,Y.H. (2004). Measuring intellectual capital: a new model and empirical study.Journal of Intellectual Capital, 5(1), 85-100.

Flamholtz, E. G., Bullen, M.,\& Hua, W. (2002). Human Resoure Accounting : A historical prespective and Future implications.Management Decision, 40(10), 947-954.

Guthrie, J., Petty, R.,\& Johanson, U. (2001). Sunrise in knowledge economy : managing, measurement and Reporting.Accounting, Auditing \& Accountability Journal, 14(4), 366 - 382.

Kannan, G.,\& Aulbur, W. G. (2004). Intellectual capital : measurement effectiveness.Journal of Intellectual Capital, 5(3), 389-413.

Kenndy, F.(1998). Intellectual capital in valuing intangible assets.Team Performance Management, 4(4), 121-137.

Marr, B. (2008).Impacting Future Value: How to Manage your Intellectual Capital, Published by The Society of Management Accountants of Canada.The American Institute of Certified Public.

Roos, G., Roos, J., Dragonetti, N., \& Edvinsson, L. (1997).Intellectual Capital: Navigating in the New Business Landscape. Macmillan Business, London.

Sanchez, P., Chaminade, C., \& Olea, M. (2000). Management of Intangibles : an Attempt to Build a theory.Journal of Intellectual Capital, 1(4), 312-327.

Seetharaman, A., Sooria, H.H.B.Z.,\& Saravanan, A. S. (2002). Intellectual capital accounting and Reporting in the knowledge economy. Journal of Intellectual Capital, 3(2), 128-148.

Sullivan, J. P. H., \&Sullivan, S. P. H. (2000). Valuing intangible companies : an intellectual capital approach.Journal of Intellectual Capital, 1(4), 328-340.

Tayles, M., Bramley, A., Adshead, N.,\& Farr, J. (2002). Dealing with the management of intellectual capital : The potential role of strategic management accounting.Accounting, Auditing \& Accountability Journal, 15(2), 251-267.

Tissen, R., Andriessen, D.,\&Deprez, F.L. (1998).Creating the $21^{\text {st } C e n t u r y ~ C o m p a n y: ~ K n o w l e d g e ~}$ Intensive, People Rich, Value-based Knowledge Management. Addison Wesley Lingman, Netherlands.

Vasile, B. (2008). Factors of the earning functions and their influence on the intellectual capital of an organization. Journal of applied Quantitative methods, 3(4), 366-374. 